\title{
Editorial Expression of Concern: Experience with alendronate treatment for 7 years among Japanese men with osteoporosis or osteopenia and clinical risk factors for fractures
}

\author{
Jun Iwamoto ${ }^{1} \cdot$ Mitsuyoshi Uzawa² $^{2}$
}

Published online: 18 June 2021

(c) International League of Associations for Rheumatology (ILAR) 2021

\section{Editorial Expression of Concern: Clin Rheumatol (2016) 35:205-212 \\ https://doi.org/10.1007/s10067-014-2812-y}

Following receipt of a concern from a reader about this article [1], the Editor-in-Chief is issuing an editorial expression of concern to highlight the large overlap between this article and another article by the same author group [2]. Whilst there is a high percentage of overlap, the Editor-inChief considers this article to be sufficiently novel to warrant its inclusion in the scientific record. Jun Iwamoto has not responded to correspondence from the Editor-in-Chief or publisher. The Editor-in-Chief and the publisher were not able to obtain a current email addresses for Mitsuyoshi Uzawa.

\section{References}

1. Iwamoto J, Uzawa M (2016) Experience with alendronate treatment for 7 years among Japanese men with osteoporosis or osteopenia and clinical risk factors for fractures. Clinical Rheumatology 35(1): 205-212

2. Iwamoto J, Sato Y, Uzawa M, Takeda T, Matsumoto H (2010) Experience with alendronate treatment for four years among Japanese men with osteoporosis or osteopenia and clinical risk factors for fractures. Therapeutics and Clinical Risk Management 6:593-600

Publisher's note Springer Nature remains neutral with regard to jurisdictional claims in published maps and institutional affiliations.

The online version of the original article can be found at https:// doi.org/10.1007/s10067-014-2812-y

Jun Iwamoto

jiwamoto@a8.keio.jp

1 Institute for Integrated Sports Medicine, Keio University

School of Medicine, 35 Shinanomachi, Shinjuku-ku,

Tokyo 160-8582, Japan

2 Department of Orthopaedic Surgery, Keiyu Orthopaedic

Hospital, Gunma, Japan 